\title{
Profunda análise da relação política e media
}

\section{Deep analysis of politics and media relationship}

\author{
ÉLMANO RICARTEa \\ Universidade Católica Portuguesa, Programa de Doutorado em Ciências da Comunicação. Lisboa, \\ Portugal
}

FIGUEIRAS, Rita. A mediatização da política na era das redes sociais. Lisboa: Alêtheia Editores, 2017. 112 p. ISBN: 97\$9\$9622907S

\begin{abstract}
RESUMO
Apresenta-se a resenha crítica da obra A mediatização da política na era das redes sociais recentemente lançada em Portugal. Tecemos comentários sobre a sua importância para os estudos nos processos de mediatização da política.
\end{abstract}

Palavras-chave: Mediatização, política, redes sociais

\section{ABSTRACT}

We present a critical review of the work A mediatização da política na era das redes sociais, recently published in Portugal. Following the author, we comment the book and its importance for studies on the process of politics mediatization.

Keywords: Mediatization, politics, social networks a Doutorando em Ciências da Comunicação pela Universidade Católica Portuguesa (UCP), bolsista da Capes. Graduado em Jornalismo e em Rádio e TV pela Universidade Federal do Rio Grande do Norte (UFRN), Brasil, com graduação sanduíche na UCP. Orcid: http://orcid.org/0000 -0002-8638-3529. E-mail: ricarteazevedo@gmail.com 


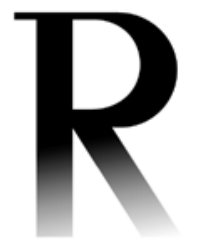

${ }^{1}$ Em Portugal, utiliza-se o termo media para designar o plural de medium (do latim, meio). Desse derivam mediatização, mediático.

Enquanto isso, no Brasil o plural de mídia seria mídias.

${ }^{2}$ Professora associada do doutorado em Ciências da Comunicação da Universidade Católica Portuguesa. Coeditora do livro Beyond the internet: unplugging the protest movement wave, publicado em 2015. Tem desenvolvido pesquisas sobre a política e os media, principalmente sobre o papel dos comentadores de política, tema de sua tese de doutoramento. É professora visitante na Universidade de São Paulo, Brasil, e na Södertörn University, Suécia.
CRESCENTE E INCONTESTÁVEL presença dos media ${ }^{1}$ nas práticas
comunicacionais de diversas instituições sociais (Ciência; Educação;
Política; Família etc.) ou nas práticas dos indivíduos (relacionamentos de grupos; relacionamentos interpessoais etc.) têm produzido debates sobre as possíveis alterações sociais e culturais em ambos os casos. Nas Ciências da Comunicação, os estudos da Mediatização têm buscado compreender tais alterações. O mais recente livro da professora doutora Rita Figueiras ${ }^{2}$, intitulado $A$ Mediatização da política na era das redes sociais, traz-nos reflexões profundas sobre o encontro e relacionamento dessa instituição tão importante para nossa sociedade com os media.

O livro divide-se em três partes, sendo a primeira "A lógica da política", "A mediação da política" a seguinte e a última "A mediatização da política", a qual subdivide-se em outras três partes: "A lógica dos media e a primeira ordem de mediatização"; "A mediatização reflexiva" e "A caminho da colonização da política pelos media?".

Na primeira parte, "A lógica da política", nos é apresentado o funcionamento do sistema político a partir de um grande levantamento de referências bibliográficas - como Meyer (2002), Pennings et al. (2006) e Esser (2013). Ou seja, discute-se a lógica da política, seu sistema, seus mecanismos internos, seus atores, suas práticas e estratégias institucionalizadas ao longo do tempo, seu tempo de gestão dos acontecimentos etc. Importa destacar que uma das características principais desse sistema a partir dessa lógica é a busca por visibilidade na esfera pública. A autora relata que, antes do relacionamento mais ostensivo com os media, havia mais interesse e perspectiva de disputa de ideologias para governar. Depois, o foco volta-se para a imagem de uma personalidade dentro do partido, sua credibilidade, seu nível de confiabilidade para ser um bom político. Nesse contexto, surge um tipo específico de política, conforme explica o livro, a "política de confiança” (Thompson, 2005). A partir dela, os debates políticos ressaltam mais os escândalos e temas de ordem pessoal dos políticos que a vida coletiva em sociedade como anteriormente. A prova disso é demonstrada na obra com a listagem de vários escândalos históricos envolvendo políticos em vários países da Europa e das Américas. Sejam os escândalos políticos ou da vida particular, ambos são deliberadamente abordados intensamente em anos de eleições ou não.

Dando continuidade a esse ponto abordado na parte anterior, a professora Rita Figueiras avança para a segunda seção, "A mediação da política”. Aqui, ela considera que acontece a primeira forma de relacionamento com os media (compreendidos como os meios de comunicação tradicionais como o jornalismo impresso, o rádio e, principalmente, a televisão). Nesse momento, eles são vistos como mediadores entre a esfera pública e os políticos. Acresce ainda que 
os investigadores apontados pela professora acreditam em uma neutralidade desse processo de mediação da política, no qual o ethos dela é transmitido sem uma forte interferência do meio de comunicação.

Apesar disso, essa relação já produz algumas alterações na forma como a política é assimilada. Se antes somente em grandes eventos públicos era possível conhecer o governante, a partir da mediação há uma interação simbólica com a representação dele. Apesar de a professora não ter mencionado Walter Benjamin (1994), observamos uma relação com a "perda da áurea" dos governantes ao mesmo tempo que ocorre sua aproximação com o público a partir de sua mediação. Como é mencionado no livro, o político entra na casa dos cidadãos em sua privacidade e fala de forma mediada com eles. Adiciona-se a isso que, nessa maneira de comunicação, cada vez mais a obtenção de informações sobre a política passa a ser mediada. Isto é, passa-se a conhecer mais política quase que exclusivamente pelos meios de comunicação.

Na terceira seção, o livro aborda "A mediatização da política". Na primeira parte, "A lógica dos media e a primeira ordem de mediatização", a autora desenvolve a ideia de que os media aproximam-se da política como "tradutora" de sua lógica, apresentando essa instituição social com uma aparência mais "familiar", segundo os procedimentos da atividade jornalística (Marcinkowski, 2014; Cook, 2005; Esser, 2013). Ao mesmo tempo, o jornalismo passa a ser mais interpretativo e menos descritivo, como era anteriormente. Isso é apontado como consequência de uma maior profissionalização da atividade com a elevação do grau de escolaridade. Surge, assim, uma maior especialização de jornalistas na política.

Como resultado, a autora acredita ter se configurado uma política mediatizada, na qual a busca por informar com base em características familiares (ligadas ao formato de entretenimento) levou a uma elevada aplicação da lógica da mídia sobre a lógica da política. Nesse caso, com a presença cada vez maior de jornalistas na política, aumentou a intervenção do jornalismo com uma política apresentada não como ela é em si mesma, mas sob a leitura realizada pelos media noticiosos, principalmente televisivos com os sound bites (declarações cortadas da fala original). Em outras palavras, cada vez menos o discurso político passou a ser televisionado por completo para caber na agenda mediática com seu timing próprio.

A autora retoma que devido à política de confiança já identificada na mediação, cujo foco está mais na personalidade dos políticos e menos no debate ideológico, criam-se, para as peças noticiosas, cenários de dramas com os escândalos políticos e pessoais, acrescidos de uma narrativa de saga na disputa eleitoral, com o claro intuito de chamar atenção. Reduz-se, conforme explica o livro, a qualidade da política apresentada na esfera pública, promovendo um desinteresse coletivo sobre esse importante elemento social. 
Por isso, tentando chamar atenção do público e garantir a visibilidade tão desejada, a lógica da política começa a adotar a lógica dos media, rendendo-se e moldando suas práticas ao timing mediático. Logo, muitos políticos passaram a ser mais figuras públicas que políticas, tornou-se mais importante uma imagem ser atrativa aos media que possuir um forte perfil e abriu-se espaço a uma política de espetáculo. Essas são algumas das temáticas abordadas na seção seguinte, "A mediatização reflexiva". Também nesse enredo, a professora argumenta que aparece a figura do spin doctor (Meyer, 2002), especialistas na área de política com comentários e análises sobre os acontecimentos atuais e suas projeções nos demais contextos sociais.

Ao demais, essa seção também aborda brevemente o impacto da internet na mediatização da política, produzindo alguma redução na forte intermediação já alcançada pelos media tradicionais (Marcinkowski, 2014). Dessa forma, a internet, com suas várias formas de produção de conteúdo e de lógicas, é apontada como um suplemento, principalmente ao conteúdo produzido pelos media televisivos.

O passo seguinte apontado no livro seria uma colonização das práticas políticas, como discute a última seção, "A caminho da colonização da política pelos media?". Aqui, configura-se uma adaptação completa à lógica dos media. Não se trata apenas de adotar as regras dos media para atrair sua cobertura, mas também de aderir à cultura mediática. Se antes o perfil do político moldava-se à lógica dos media, agora ele nasce e é construído nos programas de televisão, por exemplo. Na mesma medida, as decisões políticas, cada vez mais tomadas de imediato, e suas formas de apresentar são tratadas por profissionais de media training para que os discursos políticos sejam melhor assimilados pelo público em suas entrevistas com jornalistas, como também nas suas oratórias com cidadãos. De outra forma, o que é dito pela autora é que a política tem sido cada vez menos uma reflexão profunda para responder ao tempo mediático.

Com isso, do que podemos extrair dessa obra, os políticos, considerando-se sua proximidade com os media tradicionais, alteraram-se tanto em sua forma de se apresentar (sua imagem, seu ethos profissional) como também nos discursos proferidos ao público. Por trás disso, fica patente que todas as alterações passadas são em busca de um sobreviver, uma legitimação a partir dos meios de comunicação, vistos como parte da esfera pública.

O livro chega ao resultado de que, com o avanço da mediatização da política, pode destacar-se uma outra forma de fazer política: a política pop (Mazzoleni; Sfardini, 2009). Nessa, a performance frente aos media é mais importante, passando uma imagem mais popular, próxima da realidade e dos gostos das massas. A autora recorda ainda que, apesar disso, muito tem sido discutido a respeito desse tipo de política também ter motivado a falta de interesse e gerado pouca 
credibilidade na atividade política. Eis um preço elevado pago diante de toda a visibilidade desejada.

Há ainda um alerta de que esse processo pode ser diferente de acordo com vários fatores, como o tipo de democracia e o nível de profissionalização em determinado território, mostrando que a permeabilidade da mediatização não é tão uniforme como a autora discute em suas conclusões.

Acresce ainda que, embora o sistema político tenha feito tal simbiose com a lógica dos media, há pontos internos que não são completamente revelados como, por exemplo, a forma de atuar e de se organizar de muitos partidos. Isso revela que, de alguma maneira, a lógica da política ainda mantém parcialmente sua identidade.

Ora, a parte do explicitado no livro, somos levados a refletir superficialmente sobre a relação dos media e da política no Brasil. Devido aos crescentes escândalos mediáticos, vemos a empatia de alguns meios de comunicação sendo maior com determinadas figuras políticas e menor com outras quando também praticam desvios de conduta. Que interesses motivam tal atenção mais a uns do que a outros se a parcialidade era supostamente uma característica da lógica dos media? Devemos lembrar que por trás da relação media e política no Brasil estão grupos econômicos, os quais financiam as campanhas eleitorais dos partidos. Logo, quando os anseios de tais grupos não são atendidos pelo governo eleito, averígua-se aquilo que poderíamos chamar de uma revanche mediática. $\mathrm{Ou}$ seja, aumenta-se propositadamente a mediatização dos escândalos para tornar mais ainda visíveis os casos de desvio de conduta sejam eles em âmbito de vida particular, pública ou política.

Muito embora saibamos que o patrimonialismo e a corrupção são práticas recorrentes há muito tempo no Brasil, as abordagens mediáticas não colaboram para o esclarecimento definitivo à população sobre seu papel enquanto cidadãos. Muito pelo contrário, acaba por causar um desinteresse e uma redução da importância da política a partir da mediatização (como visto no livro da professora Rita Figueiras).

Além disso, ressaltamos que as atividades políticas ${ }^{3}$ não são mediatizadas (tornadas visíveis) na agenda dos media noticiosos por interesses dos grupos mencionados. O que sobra então como alternativa para complementar a visibilidade (lê-se mediatização) vigente? Em nossa tese de doutoramento (em fase de conclusão), temos observado a utilização dos novos media (redes sociais online) e das novas tecnologias (tablets e smartphones) para complementação da mediatização realizada nos media tradicionais. Apesar de não ser focada na mediatização da política, mas na mediatização da cultura popular, acreditamos que possa haver alguma semelhança com o que estudamos. Dizemos isso pois vemos que políticos têm utilizado cada vez mais as novas ferramentas de comunicação para realizar o
${ }^{3} \mathrm{O}$ que pensamos como política retoma o pensamento grego clássico, no qual a palavra aponta para o termo polis (interesses da coletividade). 


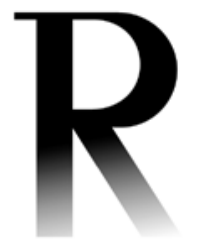

${ }^{4}$ Compreendemos cidadão como um sujeito ativo e consciente de seu papel em sociedade e não passivo ou apático à vida coletiva. $\mathrm{Ou}$ seja, seu envolvimento com uma determinada ferramenta mediática não é o determinante para ele ser um cidadão, mas é o meio para concretizar sua participação já iniciada ou latente no off-line.

debate político com seus pares e com os cidadãos ${ }^{4}$. Os cidadãos, por sua vez, têm se agrupado nas redes sociais online para organizar planos de ação coletiva. Dessa forma, ambos buscam um diálogo mais plural, como deve ser no sistema político.

Em suma, na mediatização da política com os novos media e novas tecnologias, seria possível haver alguma visibilidade e legitimação da política? Seria possível o sistema político agir conforme sua própria lógica de debate ideológico e ainda assim não perder tanto de si para atender a mediatização? Bem, essas e tantas outras perguntas não podemos responder aqui, afinal nosso propósito tem como foco o livro apresentado.

Sendo assim, essa é seguramente uma obra importante para aqueles que estudam a comunicação política com uma rica literatura sobre mediatização política do norte da Europa. Ora, também podemos considerar que seja um livro indicado aos próprios jornalistas para que compreendam o sistema no qual estão inseridos e também a lógica que os rege perante outros, como o sistema e a lógica da política. Com certeza também é uma obra para políticos refletirem sobre as alternativas para serem realmente políticos, não figuras colonizadas pela mediatização. $\mathbf{M}$

\section{REFERÊNCIAS}

BENJAMIN, W. A obra de arte na era de sua reprodutibilidade técnica. In:

Magia e técnica, arte e política. 7. ed. São Paulo: Brasiliense, 1994. p. 165-196.

COOK, T. E. Governing with the news: the news media as a political institution. 2. ed. Chicago: University of Chicago Press, 2005.

ESSER, F. Mediatization as a challenge: media logic versus political logic. In: KRIESI, H. et al. Democracy in the age of globalization and mediatization. Basingstoke: Palgrave, 2013. p. 155-176.

MARCINKOWSKI, F. Mediatisation of politics: reflections on the state of the concept. Javnost, Ljubljana, v. 21, n. 2, p. 5-22, 2014. DOI: 10.1080/13183222.2014.11009142

MAZZOLENI, G.; SFARDINI, A. Da "Porta a porta" a "Lisola dei famosi". Bologna: il Mulino, 2009.

MEYER, T. Media democracy: how the media colonize politics. Cambridge: Polity, 2002. PENNINGS, P.; KEMAN, H.; KLEINNIJENHUIS, J. Doing research in political science: an introduction to comparative methods and statistics. London: Sage, 2006. THOMPSON, J. B. The New Visibility. Theory, culture \& society, Cambridge, v. 22, n. 6, p. 31-51, 2005. DOI:10.1177/0263276405059413

Artigo recebido em 21 de julho de 2017 e aprovado em 18 de agosto de 2017. 